\title{
STABILITY OF SYNTHESIZED SILVER NANOPARTICLES IN CITRATE AND MIXED GELATIN/CITRATE SOLUTION
}

\author{
Jana Kavuličováa, ${ }^{a *}$, Anna Mražíková ${ }^{b}$, Oksana Velgosová ${ }^{b}$, \\ DANA IVÁNOVÁa, MARTINA KuBOVČÍKOVÁ ${ }^{c}$ \\ ${ }^{a}$ Institute of Metallurgy, Faculty of Materials, Metallurgy and Recycling, Technical University of Kosice, Slovakia \\ ${ }^{b}$ Institute of Materials, Faculty of Materials, Metallurgy and Recycling, Technical University of Kosice, Slovakia \\ ${ }^{c}$ Institute of Experimental Physics, Slovak Academy of Sciences, Kosice, Slovakia \\ * corresponding author: jana.kavulicova@tuke.sk
}

ABstract. The study focuses on an investigation of the influence of both citrate and mixed gelatin/citrate as a reductant and stabilizer on the colloidal stability of silver nanoparticles (AgNPs) synthesized by a chemical reduction of $\mathrm{Ag}^{+}$ions after a short- (7th day) and long- (118th day) term storage. Formed AgNPs were characterized by a UV-vis Spectroscopy, Transmission Electron Microscope (TEM), Dynamic light scattering (DLS) and Zeta-potential (ZP). The obtained results revealed that a short-term stability of the synthesized AgNPs was greatly influenced by a citrate stabilizer with the absence of gelatin. Smaller-sized AgNPs (average particle diameter of $3 \mathrm{~nm}$ ), roughly spherical in a shape, were obtained with a narrow size distribution. The very negative value of the Zeta-potential confirmed a strong stability of the citrate capped AgNPs. However, a surface coating of the AgNPs by a gelatin/citrate stabilizer was found to be a dominant contributor in improving a long-term stability of the AgNPs (average particle diameter of $26 \mathrm{~nm}$ ). The use of gelatin in mixed stabilizer solution provided the AgNPs with higher monodispersity and a controllable size after both the short and long-term storage.

KEYWORDS: silver nanoparticles; sodium citrate; gelatin; size; stability.

\section{INTRODUCTION}

The fabrication of highly characterized nanomaterials requires a developing of their specific physical and chemical properties. Among these nanomaterials, especially silver containing nanocomposites has a wide range of potential applications in diverse areas, such as, electronics, catalysis [1, cosmetics, wastewater treatment, textile industry and biomedical devices [2].

Many practical applications require stable silver nanoparticles (AgNPs) dispersions. The improving of significant parameters, which influence the stability of silver nanoparticles (AgNPs) against an aggregation state, is an essential task in the optimization of the AgNPs synthesis [3, 4. There are factors that influence the stability of AgNPs, such as the concentration of the precursor, $\mathrm{pH}$, temperature, order of mixing of reactants and stabilizers [6, 7]. For example, different kinds of stabilizers/capping agents, such as surfactants, polymers and reducing agents, are used for the surface modification of AgNPs during their synthesis to control the size, morphology, stability, and physicochemical properties of AgNPs [8]10].

Silver nanoparticles are typically prepared through the reduction of a silver precursor using chemical or physical means 4, 9. Chemical reduction of a silver nitrate salt in an aqueous media by a reducing agent in the presence of a surfactant is a facile synthetic method. Many authors have also reported that sodium citrate serves both as a reducing and stabilizing agent in the preparation of silver nanoparticles [1-13. Among stabilizers, gelatin has also been used as a natural biopolymer for the stabilization of inorganic nanoparticles and is known to be biodegradable in physiological environments [4, 14. The novelty of this study lies in its modified approach to the synthesis of AgNPs by the surface-protecting chemical reduction of the silver nitrate using a mixed gelatin/sodium citrate solution both as a stabilizer and reducing agent for AgNPs. The effects of reducing agent and stabilizer on the particle size, size distribution, shape and stability of AgNPs were evaluated after a short- (7th day) and long- (118th day) term storage and compared to those of AgNPs synthesized by using the standard reduction of silver salt in sodium citrate.

\section{MAterials AND METHOdS}

\subsection{Chemicals}

Silver nitrate (p.a. Mikrochem), sodium citrate (p.a. Lachema), gelatin (p.a. Lachema) were used for the synthesis of the silver nanoparticles without any further purification. Demineralized water (conductivity $0.3 \mu \mathrm{S} \mathrm{cm}^{-1}$ ) from Demiwa 3 rosa (Watek) was used to prepare the solutions.

\subsection{SyNTHESIS OF SILVER NANOPARTICLES BY USING SODIUM CITRATE METHOD}

Chemically synthesized AgNPs were prepared using a chemical reduction method as demonstrated [15]. Aqueous $\mathrm{AgNO}_{3}(0.29 \mathrm{mM})$ was used as the $\mathrm{Ag}^{+}$salt precursor. To this solution, sodium citrate $(1 \%)$ was added drop by drop as a reducing agent. During the synthesis, the solution was heated to an elevated temperature $\left(\sim 90^{\circ} \mathrm{C}\right)$ and mixed vigorously until a colour change was evident. The $\mathrm{pH}$ of the prepared AgNPs colloids was close to 7 . 


\subsection{Synthesis OF SILVER NANOPARTICLES BY USING MIXED GELATIN/SODIUM CITRATE METHOD}

The experiment was modified using the same conditions of the previous method with a reaction of aqueous $\mathrm{AgNO}_{3}(0.29 \mathrm{mM})$ and sodium citrate $(1 \%)$, but with gelatin. A $0.01 \%$ gelatin concentration was added to the solution of $\mathrm{AgNO}_{3}$ prior to the addition of a reducing agent in order to prevent the particle agglomeration.

\subsection{Methods For Determination}

The formation of AgNPs was monitored by measuring the UV-vis spectra with the UNICAM UV/vis Spectrometer UV4. The absorbance was recorded after $5 \mathrm{~h}, 24 \mathrm{~h}$ and on the 3rd, 7th, 10th, 15th, 23th, 30th, 90th, 118th and 150th day. Transmission Electron Microscope (TEM) (JEOL model JEM-2000FX microscope operated at an accelerating voltage of $200 \mathrm{kV}$ ) was used to determine the size and the morphology of AgNPs on the 7th and 118th day. The samples were prepared by placing a drop of the colloidal solution of AgNPs on a carbon-coated nickel grid and completely dried at a room temperature. Dynamic Light Scattering (DLS) was carried out to estimate the hydrodynamic size of AgNPs in a suspension on the 7 th and 118th day. The samples were measured using Zetasizer Nano ZS (Malvern Instruments). The zeta $(\zeta)$ potential was determined using the Laser Doppler Electrophoretic measurement technique with a scattering angle of $173^{\circ}$ at $25 \pm 0.1^{\circ} \mathrm{C}$

\section{Results AND Discussion}

The inset of Figure 1 shows the photographs of samples obtained under different conditions. In the reaction of $\mathrm{AgNO}_{3}$ with citrate without gelatin, silver colloids turned pale yellow-brown. It implied the formation of AgNPs, while the addition of gelatin to $\mathrm{Ag}^{+}$solution led to the change of the solution colour to a dark brown (after $20 \mathrm{~min}$ ), indicating the significant influence of gelatin in terms of its role as a reducing agent on the final colour of the AgNPs dispersion. Similarly, the ability of gelatin as a good reducing agent in the synthesis of AgNPs was reported in the study [14.

The synthesis of AgNPs was confirmed by a UV-vis spectroscopy. The surface plasmon resonance (SPR) bands for AgNPs have been reported to be in the range of $380-450 \mathrm{~nm}$. The SPR bands are influenced by size, shape, morphology and composition of the prepared AgNPs [16. The symmetry and broadness of the absorption bands may be related to various shaped and/or sized AgNPs [17, 18. The absorption spectra (Figure 1 a) of silver colloids without gelatin displayed the symmetric and broader SPR peak of a very low intensity with a no significant spectral shift (from 420 to $422 \mathrm{~nm}$ ) after a short storage (range 3-23 days) indicating a synthesis of uniform and stable AgNPs. Based on the symmetry of the peak, it is assumed that the majority of synthesized AgNPs did not aggregate. In the case of adding gelatin to the $\mathrm{Ag}^{+}$solution, the asymmetric
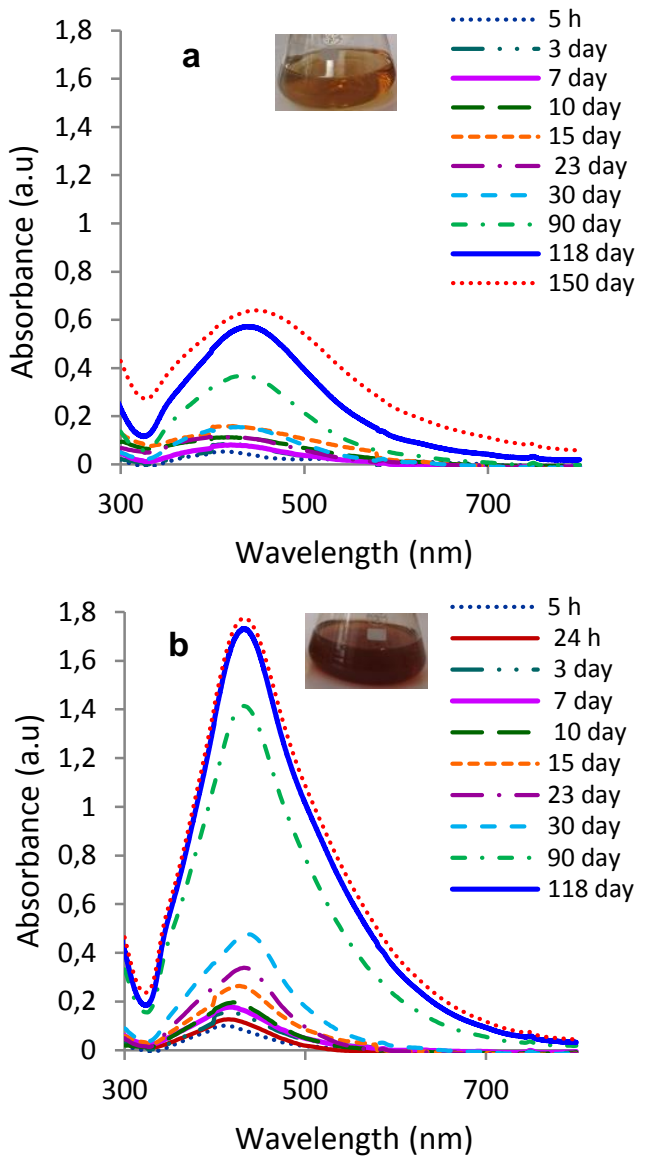

FiguRE 1. UV-vis spectra of AgNPs a) capped with citrate, b) capped with gelatin/citrate as a function of reaction time, c) coated with different capping agents after 7 days. The inset shows the color change upon synthesis of AgNPs.

and narrower SPR band with a significant spectral shift (from 414 to $432 \mathrm{~nm}$ ) after a short storage revealed a less uniform particle size distribution (Figure 1 $1 \mathrm{~b}$ ) as compared with those seen in the absence of gelatin. However, insignificant changes in the red-shift of the SPR band (from 432 to $434 \mathrm{~nm}$ ) were observed after a long storage (range 30-150 days) suggesting a good stability of the prepared AgNPs for a long time. The intensity of the SPR bands gradually increased over time due to the continuous synthesis of AgNPs [19, 20]. As shown in Fig. $1 b$, the SPR bands were proportionally more heightened than in Fig.1a, which corresponds to the combined effects of citrate/gelatin as reducing agents resulting to a more intensive colour of the AgNPs colloid. According to the authors [21, 22], the SPR peak located between 410 and $450 \mathrm{~nm}$ during the synthesis of AgNPs might be attributed to spherical or roughly spherical shaped silver nanoparticles (Figure 1). Figure 1: compares the SPR bands of the AgNPs coated with citrate, gelatin and gelatin/citrate after 7 days of storage. It is interesting to note the significant reduction ability of gelatin in the synthesis of AgNPs.

The particle size distribution and the shapes of prepared AgNPs were confirmed by a TEM analysis on the 7 th and 118th day. The TEM images revealed roughly 


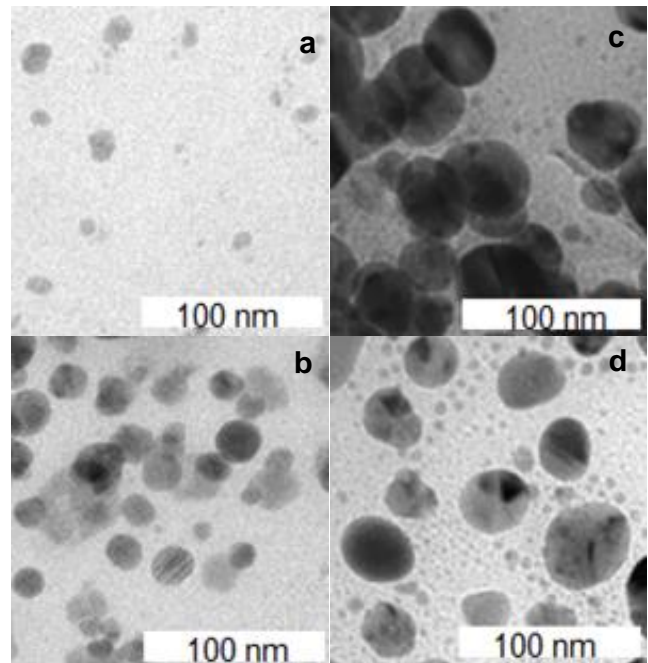

Figure 2. TEM images of AgNPs prepared using a) citrate and b) gelatin/citrate on 7th day, c) citrate and d) gelatin/citrate on 118th day.

spherical shaped AgNPs in both the absence and the presence of gelatin (Figure 2p. Smaller-sized AgNPs were obtained after their short storage (Figure $2 \mathrm{~kb}$ ) and gelatin/citrate capped AgNPs showed a higher degree of monodispersity (Figure 2 $\mathrm{bd}$ ) than AgNPs without gelatin, significantly after 118 days (Figure 2k).

The TEM images (on the 7th day) displayed AgNPs with an average particle diameter of 3 and $15 \mathrm{~nm}$ without and with gelatin, respectively (Figure $3 \mathrm{ab}$ ). According to the results, smaller AgNPs were prepared with a narrow size distribution, the size ranged from 1-22 nm (Figure $3 \mathrm{a}$ ) when only citrate was used as a reducing and stabilizing agent. As indicated above, TEM results confirmed that the synthesized AgNPs in the absence of gelatin are more stable after a short storage. The TEM images (on the 118th day) demonstrated that a higher percentage of the AgNPs (42\%) synthesized with gelatin are smaller than those prepared without gelatin (10\%), with the former in the range of 4 to $55 \mathrm{~nm}$ with an average diameter of $26 \mathrm{~nm}$ (Figures $2 \mathrm{~d}$ and $3 \mathrm{~d}$ ). The usage of the mixed gelatin/sodium citrate method allows a synthesis of size-controlled AgNPs. According to 23, the better control on nucleation and growth of nanoparticles is caused by a combined effect of two different reducing agents. The size of AgNPs without gelatin showed a wider range of particle size distribution (from 7 to $85 \mathrm{~nm}$ in diameter) with an average diameter of $36 \mathrm{~nm}$ (Figures 2k and 3r). This can be particularly explained by the fact that gelatin forms the coating on the surface of AgNPs during the particle growth process and prevents an aggregation through a steric hindrance due to its high molecular weight and significant surface activity [4, 24].

It seems that the stability of sterically stabilized silver colloids in the presence of gelatin predominates over the electrostatic stabilization caused by a capping of citrate onto the surface of AgNPs. Moreover, the addition of excess citrate as a reducing agent in the absence of

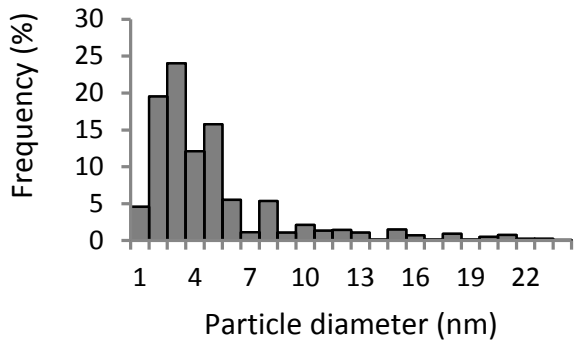

a
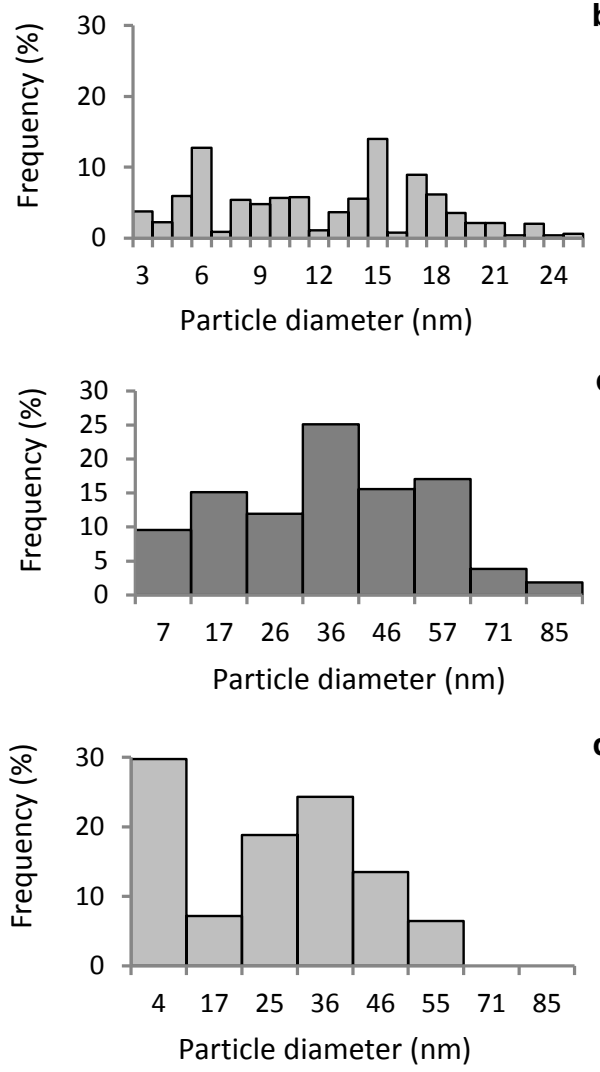

FiguRE 3. The size histogram of AgNPs prepared using a) citrate and b) gelatin/citrate on the 7th day, c) citrate and d) gelatin/citrate on the 118 th day.

gelatin forms a larger AgNPs in comparison with AgNPs made with the presence of gelatin (Figure 2). Likewise, the effect of higher citrate concentrations during the growth of existing AgNPs nucleis through the surface reduction of silver ions has also been described by [25]. This supports the observation in UV-vis spectra that gelatin/citrate capped AgNPs exhibited a long-term stability.

In addition, the average hydrodynamic diameter, polydispersity index (PDI) and Zeta potential of AgNPs in dispersion gathered by the DLS both in the absence and presence of gelatin are shown in Table 1. The sizes observed by the DLS (Figure 4 $\mathrm{ab}$ ) are significantly higher than the sizes obtained by the TEM. This could be attributed to the effective coating of gelatin and/or citrate on the surface of AgNPs. The AgNPs in colloids are electrostatically stabilized because of their negative surface charge arising from the presence of oxo- or hydroxo-functional groups in the citrate on the AgNPs surface [26]. 


\begin{tabular}{|c|c|c|c|c|c|c|c|c|c|}
\hline \multirow{3}{*}{$\begin{array}{l}\text { Sample } \\
\text { name }\end{array}$} & \multirow{3}{*}{$\begin{array}{c}\mathrm{pH} \text { of } \\
\text { silver } \\
\text { colloid }\end{array}$} & \multicolumn{4}{|c|}{$t=7$ days } & \multicolumn{4}{|c|}{$t=118$ days } \\
\hline & & \multicolumn{2}{|c|}{$\begin{array}{c}\text { Z-average } \\
\text { diameter }(\mathrm{nm})\end{array}$} & \multirow[t]{2}{*}{$\begin{array}{l}\text { Z-potencial } \\
(\mathrm{mV})\end{array}$} & \multirow[t]{2}{*}{$\overline{\mathrm{PDI}}$} & \multicolumn{2}{|c|}{$\begin{array}{c}\text { Z-average } \\
\text { diameter }(\mathrm{nm})\end{array}$} & \multirow[t]{2}{*}{$\begin{array}{l}\text { Z-potencial } \\
(\mathrm{mV})\end{array}$} & \multirow[t]{2}{*}{ PDI } \\
\hline & & TEM & DLS & & & TEM & DLS & & \\
\hline $\operatorname{AgNPs}_{(a)}$ & 6.77 & 3 & 103 & -37.3 & 0.28 & 36 & 164 & -10.5 & 0.44 \\
\hline $\operatorname{AgNPs}_{(b)}$ & 6.93 & 15 & 146 & -7.8 & 0.2 & 26 & 174 & -19.7 & 0.21 \\
\hline
\end{tabular}

TABLE 1. Average values of AgNPs diameter determined by DLS method and from TEM images, PDI and Z-potencial of AgNPs colloids on 7 th and 118th day.
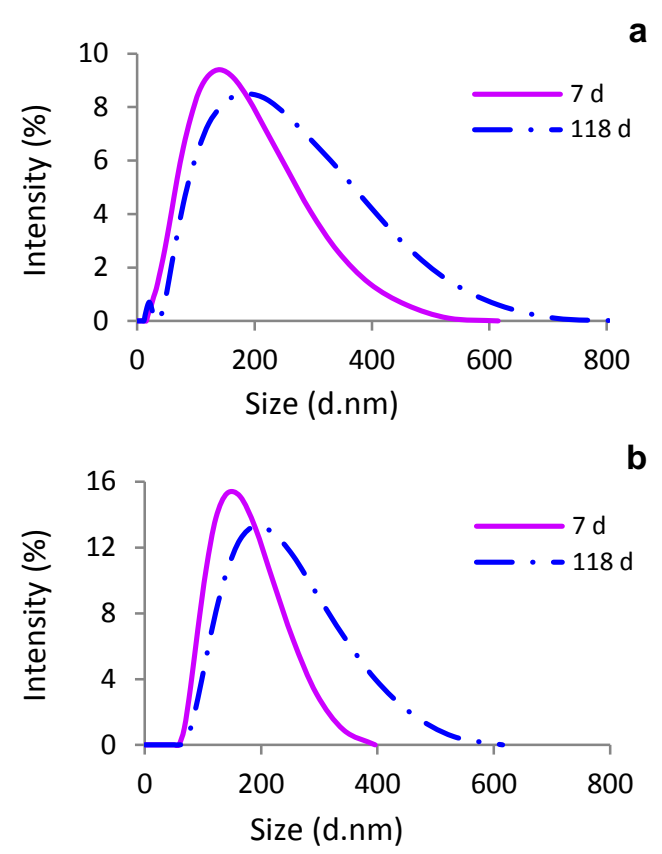

Figure 4. DLS size distribution of AgNPs prepared using a) citrate b) gelatin/citrate on 7th and 118th day.

The Zeta potential analysis also confirmed the strong stability of AgNPs without gelatin $(-37.3 \mathrm{mV})$ after a short storage due to the citrate layer on the surface of AgNPs through an electrostatic interaction. However, the addition of gelatin resulted in a significantly lower negative value of the zeta potential $(-7.8 \mathrm{mV})$.

It probably relates to a possible interaction between amino groups of gelatin and carboxyl groups of citrate coated on the surface of AgNPs. The stability of AgNPs coated by organic coatings with varying molecular weight and functional groups is achieved through the adsorption or covalent attachment. The attachment of the stabilizer to AgNPs surface is probably related to their interaction strength [26]. Effectiveness of the bounded citrate with gelatin was enhanced on the surface of AgNPs after a long storage and proved by the fact that the Z-potential was found to be $-19.7 \mathrm{mV}$.

Electrostatic stabilization of AgNPs can be reduced by the presence of counterions in the colloid [26]. The presence of cations (e.g. $\mathrm{Na}+$ ) in the reducing agent could partially destabilize the citrate coated AgNPs after long storage, this is confirmed by the increased negative value of the zeta potential $(-10.5 \mathrm{mV})$.
A possible reaction scheme expresses the formation of the citrate capped AgNPs (1) by a faster reduction in comparison with the formation of the gelatin capped AgNPs (2) achieved by a slower reduction [14]. If the course of these reactions is considered, the synthesis of the gelatin/citrate capped AgNPs can take place through the formation of a gelatin-silver cation complex and the gelatin capped AgNPs [27]. The concentration of this complex is considerably higher than the content of the gelatin capped AgNPs. This is likely due to the partial reduction of $\mathrm{Ag}+$ to $\mathrm{Ag} 0$ using gelatin during the short reaction time for the formation of gelatin/citrate-AgNPs. These reactions can be represented by (3)- 4) (Figure 5.

The AgNPs prepared with gelatin showed considerably lower PDI of 0.2 and 0.21 as compared with the AgNPs without gelatin, PDI of 0.28 and 0.44 on the 7 th and 118th day, respectively (Table 11). The comparison of PDI values for AgNPs prepared without and with gelatin demonstrated that the synthesis of AgNPs in mixed gelatin/citrate solution produced AgNPs with higher monodispersity after both short and long-term storage.

The results of this study indicate the importance of the factors, such as stabilizer type, concentration and addition order of the reducing and stabilizer agents, reaction time and ionic strngth, that significantly affect the stability of the synthesized AgNPs in the colloid.

\section{Conclusions}

In this study, the influence of citrate and gelatin on the stability of formed AgNPs in dispersion was investigated. The modified synthesis of AgNPs through a chemical reduction of $\mathrm{Ag}^{+}$in a gelatin/citrate mixed solution was compared to the standard reduction of $\mathrm{Ag}^{+}$in citrate. The surface coating of AgNPs by a citrate stabilizer proved to be significant for achieving a shortterm stability of AgNPs in colloid. In comparison, the use of gelatin as a reducing and surfactant agent greatly increased the long-term stability of AgNPs. This shows that synthesized AgNPs exhibited improved stability through synergetic steric/electrostatic effects of the gelatin/citrate system, respectively. The mixed gelatin/sodium citrate method offers a size-controlled synthesis of monodisperse AgNPs with their potential use in a production of nanocomposite materials.

\section{ACKNOWLEDGEMENTS}

This work was financially supported by the Slovak Grant Agency (VEGA 1/0197/15). 


$$
\begin{gathered}
\operatorname{Ag}^{+}(\mathrm{aq})+\operatorname{citrate}(\mathrm{aq}) \rightarrow \text { citrate-AgNPs }(\mathrm{s})+\operatorname{citric} \text { acid }(\mathrm{aq}) \\
\mathrm{Ag}^{+}(\mathrm{aq})+\text { gelatin }(\text { gel })(\mathrm{aq}) \rightarrow \text { gelatin-AgNPs }(\mathrm{s}) \\
\mathrm{Ag}^{+}(\mathrm{aq})+\text { gelatin }(\mathrm{gel})(\mathrm{aq}) \rightarrow[\operatorname{Ag}(\mathrm{gel})]^{+}(\mathrm{aq})+\text { gelatin-AgNPs }(\mathrm{s}) \\
{[\operatorname{Ag}(\text { gel })]^{+}(\mathrm{aq})+\text { citrate }(\mathrm{aq}) \rightarrow \text { gelatin } / \text { citrate- } \operatorname{AgNPs}(\mathrm{s})+\text { citric acid }(\mathrm{aq})}
\end{gathered}
$$

FiguRE 5. A possible reaction scheme for the synthesis of AgNPs coated with the capping agents: citrate (1), gelatin (2) and gelatin/citrate (3)-4).

\section{REFERENCES}

[1] Sheng, Y. et al.: Facile Synthesis of Monodisperse Nanostructured Silver Micro-Colloids via Controlled Agglomeration and Coalescence. Nanosci. Nanotechnol., 17, 2017, p. 626-633.

[2] Keat, C.L. et al.: Biosynthesis of nanoparticles and silver nanoparticles. Bioresour. Bioprocess., 2:47, 2015, DOI:10.1186/s40643-015-0076-2

[3] Tran, Q.H., Nguyen, V.Q., Le, A.-T.: Silver nanoparticles: synthesis, properties, toxicology, applications and perspectives. Adv. Nat. Sci: Nanosci. Nanotechnol., 4, 033001, 2013, 20 pp.

[4] Ipek, Y. G. et al.: Synthesis and immobilization of silver nanoparticles on aluminosilicate nanotubes and their antibacterial properties. Appl. Nanosci., 6, 2016, p. 607-614.

[5] Sivera, M. et al.: Silver nanoparticles modified by gelatin with extraordinary $\mathrm{pH}$ stability and long-term antibacterial activity. PLoS ONE, 6, 9(8): e103675, 2014, DOI:10.1371/journal.pone.0103675

[6] Jose, M., Sakthivel, M.: Synthesis and characterization of silver nanospheres in mixed surfactant solution. Mater. Lett., 117, 2014, pp. 78-81.

[7] Römer, I. et al.: Aggregation and dispersion of silver nanoparticles in exposure media for aquatic toxicity tests. J. Chromatogr. A, 1218(27):4226-33, 2011, DOI:10.1016/j.chroma.2011.03.034

[8] Lodeiro, P. et al.: Silver nanoparticles coated with natural polysaccharides as models to study AgNP aggregation kinetics using UV-Visible spectrophotometry upon discharge in complexenvironments. Sci. Total Environ., 539, 2016, p. 7-16.

[9] Srinithya, B. et al.: Synthesis of biofunctionalized AgNPs using medicinally important Sida cordifolia leaf extract for enhanced antioxidant and anticancer activities. Mater. Lett., 170, 2016, p.101-104.

[10] Abdulla-Al-Mamun, M., Kusumoto, Y., Muruganandham, M.: Simple new synthesis of copper nanoparticles in water/acetonitrile mixed solvent and their characterization. Mater. Lett., 63, 2009, p. 2007-2009.

[11] Khanna, P. K. et al.: Synthesis and characterization of copper nanoparticles. Mater. Lett., 61, 2007, p. 4711-4714.

[12] Guzmán, M. G., Dille, J., Godet, S.: Synthesis of silver nanoparticles by chemical reduňction method and their antibacterial activity. Int. J. Chem. Biomol. Eng., 2, 2009, p. 104-111.

[13] Girilal, M. et al.: A comparative study on biologically and chemically synthesized silver nanoparticles induced Heat Shock Proteins on fresh water fish Oreochromis niloticus. Chemosphere, 139, 2015, p. 461-468.

[14] Lee, C. and Zhang, P.: Facile synthesis of gelatin-protected silver nanoparticles for SERS applications. J. Raman Spectrosc., 44, 2013, p. 823-826.
[15] Asta, S. et al.: Analysis of silver nanoparticles produced by chemical reduction of silver salt solution. Mater. Sci., 12, 2006, p. 287-292.

[16] Kelly, K. L. et al.: The Optical Properties of Metal Nanoparticles: The Influence of Size, Shape, and Dielectric Environment. J. Phys. Chem. B, 107, 2003, p. 668-677. DOI:10.1021/jp026731y

[17] Lah, N. A. C., Johan, M. R.: Facile Shape Control Synthesis and Optical Properties of Silver Nanoparticles Stabilized by DAXAD 19 Surfactant. Appl. Surf. Sci., 257, 2011, p. 7494-7500.

[18] Rashid, M. U., Bhuiyan, M. K. H., Quayum, M. E.: Synthesis of silver nano particles (Ag-NPs) and their uses for quantitative analysis of vitamin $\mathrm{C}$ tablets. J. Pharm. Sci., 12, 2013, p. 29-33.

[19] Ibrahim, H. M. M.: Green synthesis and characterization of silver nanoparticles using banana peel extract and their antimicrobial activity against representative microorganisms. J. Rad. Res. Appl. Sci., 8, 2015, p. 265-275.

[20] Velgosová, O., Mražíková, A., Marcinčáková, R.: Influence of $\mathrm{pH}$ on green synthesis of $\mathrm{Ag}$ nanoparticles. Mater. Lett., 180, 2016, p. 336-339.

[21] Jyoti, K., Baunthiyal, M., Singh, A.: Characterization of silver nanoparticles synthesized using Urtica dioica Linn. leaves and their synergistic effects with antibiotics. J. Rad. Res. Appl. Sci., 9, 2016, p. 217-227.

[22] Shankar, S. et al: Effect of reducing agent concentrations and temperature on characteristics and antimicrobial activity of silver nanoparticles. Mater. Lett., 137, 2014, p. 160-163.

[23] Agnihotri, S., Mukherji, S., Mukherji, S.: Size-controlled silver nanoparticles synthesized over the range 5-100 nm using the same protocol and their antibacterial efficacy. RSC Adv., 4, 2014, p. 3974-3983. DOI:10.1039/C3RA44507K

[24] Lin, L.-H., Chen, K.-M.: Preparation and surface activity of gelatin derivative surfactants. Colloids Surf. A: Physicochem. Eng. Asp., 272, 2006, p. 8-14.

[25] Thanh, N. T. K., Maclean, N., Mahiddine, S.: Mechanisms of nucleation and growth of nanoparticles in solution. Chem. Rev., 114, 2014, p. 7610-7630.

[26] Levard, C., Hotze, E. M., Lowry, G.V., Brown Jr., G.E.: Environmental Transformations of Silver Nanoparticles: Impact on Stability and Toxicity. Environ. Sci.Technol., 46, 2012, p. 6900-6914. DOI:10.1021/es2037405

[27] Oluwafemi, O.S., Lucwaba, Y., Gura, A., Masabeya, M., Ncapayi, V., Olujimi, O.O., Songca, S.P.: A facile completely 'green'size tunable synthesis of maltose-reduced silver nanoparticles without the use of any accelerator. Colloids Surf. B:Biointerfaces, 102, 2013, p. 718-723. 